\title{
Documentation is Documentation and Theory is Theory: A Reply to Daniel Avorgbedor's Commentary "Documenting Spoken and Sung Texts of the Dagaaba of West Africa"
}

\author{
MANOLETE MORA \\ The University of Hong Kong \\ ADAMS BODOMO \\ The University of Hong Kong
}

\begin{abstract}
In a response to an article that appeared in Empirical Musicology Review (Bodomo and Mora 2007), Avorgbedor (2007) takes issue with aspects of the paper. In our reply to Avorgbedor's response we will firstly clarify some issues raised therein and secondly address the issue about the relationship between theory, description and documentation within linguistics and musicology.
\end{abstract}

Submitted 2007 October 12; accepted 2007 October 14

KEYWORDS: West Africa, song, dance, story, oral, culture, Dagaare, Dagaaba, bawaa

\section{INTRODUCTION}

THERE are at least three ways of evaluating an academic paper. One is to clearly identify the author's objectives and then hold the author to the realization of these objectives. Another is to disregard what the author has done and suggest what $\mathrm{s} / \mathrm{he}$ might have done or what $\mathrm{s} /$ he might do in another paper. The third is a combination of the first two ways.

Daniel Avorgbedor's criticism (Avorgbedor, 2007) of the article is essentially based on the second approach, though he briefly addresses our main objective by providing pertinent background information on what the United Nations Educational Scientific and Cultural Organization (UNESCO) has done in the important area of cultural documentation. However, given the clearly stated objective of our article, which was to report on a project that set out to document, in situ, musical and linguistic practices among the Dagaaba of northwest Ghana, we believe the first approach would have been more appropriate.

Indeed one of the main objectives of our paper, namely, to report on a documentation-based project, was reiterated in various sections of the paper: "The main intention of the project is to document songs, proverbs, riddles, spoken and sung folktales, instrumental music, and dance performance..." and "One of the objectives of the field research was to obtain a body of music that would serve as a basis for comparative linguistic and musicological analysis." Clearly, from these statements, our explicit preoccupation with the reviewed article was to focus on our recording and transcription of aspects of our extensive collection of spoken and sung texts as raw materials for the benefit of scholars in linguistics and musicology. As we show in the next section the review article lost sight of the objectives and scope of our article.

\section{Documentation is Documentation and Theory is Theory:}

The most important aspect of the commentary's contribution to the debate about the documentation of cultural practices is contained in the first two pages where, under "essential contexts", it provides very useful information about UNESCO's activities in cultural preservation and conservation including their stated policy on documentation and references to publications on the subject. As the author himself has mentioned, this is "insider" information that only someone intimately connected with UNESCO would 
know (the author acknowledges that he is the country chairman of the UNESCO body dealing with issues of preservation.)

While the commentary initially acknowledges the importance of documentation, it seems to be somewhat ambivalent about the process and project of documentation more generally. Surprisingly, and somewhat contradictorily, the commentary takes issue with the title (and indeed) the whole subject matter of our paper. For example, it contains the claim that 'specific questions pertaining to theory, method and general scholarly significance of the paper are regrettably preempted and thus mitigated by the title phrase', which is, "Documenting Sung and Spoken Texts...". The commentary then goes on to say that "Documenting..." does not immediately suggest any substantial commitment to advancing general knowledge, tools, and perspectives through the employment of innovative research strategies and analysis..' This statement is simply unfounded and plainly illogical and it presumes an insight into our scholarly motivations that cannot be defended. Moreover, the commentary seems to be suggesting that only research strategies that are 'innovative' or set out to prove theories are able to 'advance knowledge'. Arguably, the truth of the matter is that good ethnography remains, while theories come and go. Researchers all too often enter the 'field' with theories to prove and become blinkered in the view that the research subject matter is there to serve the theory rather than the other way around. There is something to be said for allowing the data, in so far as it is possible, to speak for itself and to allow theory to emerge from the experience of the fieldwork and the data itself. This is the value of solid empirical research and the commentary might have done a greater service to the advancement of knowledge by showing where our data is wrong, rather than proposing that we take this or that theoretical approach. Surely, reliable documentation is the first step in conducting research that advances knowledge and the reporting of our field excursion into the Dagaare region sets out to do just that. In other contexts, under other circumstances, we would indeed be disposed toward providing more nuanced interpretations and analyses of the data with theoretical underpinnings.

\section{Further Illustrations and Clarifications}

To add to the above point about the enduring value of solid ethnography and the ephemeral nature of theory we draw on an important and emerging discussion in linguistics. Presently in linguistics there is a concern to separate documentation from other theoretical descriptive tendencies in linguistic field work, especially in ethnographic work that involves the recording, preservation and revitalization of endangered languages. For instance, Himmelmann (1998) notes the following: "I will argue against this widespread conception [ie., the lack of recognition of the difference between documentation and theory-based description and to consider them as part of a single uniform project] and in favour of a clearer separation...between these two activities." (p162). Himmelmann goes on to distinguish clearly between documentary linguistics and descriptive linguistics. One of the important reasons, which we think apt for the situation at hand is that "....any close link between these two activities has the consequence of the descriptive concept of language determining the kind of data considered relevant in language documentation" (p.168). Because we believe that data should precede and even determine theory, and not the other way around, we consider that prominence should be given to documentation in this kind of preliminary ethnographic work. Indeed, in recent work on Zhuang, an endangered language in mainland China, one of us took this approach which resulted in the extensive recording of primary field materials from this language (Bodomo and Pan 2007).

We believe that this approach involving the separation of documentation from theory and description within linguistics is equally valid for musicology and other ethnographic pursuits, especially in situations involving oral and endangered cultural practices.

Of course, we do not deny the importance of theory, and we have in other forums given theoretical attention to the interaction between tone and tune. The commentary already refers to some of these theoretical studies and even takes issue with them, however, right now we will avoid being distracted from the thrust of our reply, which primarily concerns the relationship between documentation and theory.

Before we conclude we will also briefly reply to and clarify a couple of other issues raised by the commentary, in particular, the objection to our use of the term "oral" to describe Dagaare cultural practices and their dissemination (“...it can be very misleading to label cultures prematurely as mainly oral...") and to the suggestion that written folktales and classroom and church music activities may have some role in shaping new approaches to learning and, presumably, disseminating culture. Our response is that despite the presence of some formal schooling and the Catholic Church in the region, Dagaare culture is still predominantly an oral one, and this is an irrefutable fact for people who know the region well. Even the 
Ewe culture to the south of the country that the author of the commentary knows well cannot claim to be more of a literate than an oral culture. Of course, the Dagaaba, like most other orally-based social groups, are extremely 'literate', in the sense that they have a deep knowledge of or are well-educated in their oral literature and music as the recordings of the cultural practices we have documented illustrate. Indeed, people like the Dagaaba appear more culturally literate than many from societies where the ability to read and write is the norm. This is partly the point about documenting oral culture, if only to help dispel the myths about the relationship between literacy and cultural value.

Finally, the commentary recommends some reference materials and makes suggestions as to how we might interpret the cultural meanings of the spoken and sung texts. Again, while we are most appreciative of these recommendations and suggestions, we hold the view that these are more relevant to how another, different article might have been written and, therefore, they have less value as a critique of the article in question. Readers may be assured that an appropriate and adequate account of the cultural meaning of all the spoken texts recorded during our field trip awaits a book length treatment, but clearly that was not the objective of our article.

\section{CONCLUSION}

Our documentation was intended to be comprehensive and essentially non-selective. A concern with theory or matters of cultural adjustments within the literate frameworks of educational institutions and the like would have necessitated a more selective approach to documentation, and that would have inevitably been undertaken to serve a particular theoretical perspective. To conclude, we have in this paper advocated the need for a separation between documentation and theoretical descriptions when dealing with ethnographic materials from minority and endangered cultures and to that end, our original article succeeds or fails on that basis.

\section{REFERENCES}

Avorgbedor, D., (2007). Language plots in musical spaces: A response to Adams Bodomo and Manolete Mora. Empirical Musicology Review, Vol 2, No. 3, pp 103-109.

Bodomo, A. B. \& Mora, M. (2007). Documenting spoken and sung texts of the Dagaaba of West Africa. Empirical Musicology Review, Vol. 2, No. 3, pp.81-102.

Bodomo, A.B., and Pan, Y.-Q.. (2007). A Proficiency Course in Zhuang: Fieldwork Documentation and Revitalization of a Language and Culture of Southwestern China. Hong Kong: The Linguistic Society of Hong Kong.

Himmelmann, N. P. (1998). Documentary and descriptive linguistics. Linguistics, Vol. 36, pp.161-195. 